\title{
Costing Distance Ed: Experience-Based Practices
}

Gary R. Schornack, (E-mail: gschorna@ carbon.cudenver.edu), University of Colorado at Denver Charles E. Beck, (E-mail: cbeck@uccs.edu), University of Colorado at Colorado Springs

\begin{abstract}
To respond creatively to the many new opportunities of distance education, the educational community can benefit from a comprehensive view of the distance learning system. The Process Model for Program Analysis outlines a five-step process to examine all aspects of the system: Input, Purpose, Method, Implementation, and Feedback. Inputs include physical and faculty resources, while assumptions include educational philosophy and culture. Purpose includes specific objectives and the intended audiences for the program. Method includes the medium used to convey ideas and the process used to put them together including expenditures. Implementation combines purpose, method, and estimated costs to conduct the actual program. Feedback includes follow-up with students and the community, cost-benefit analysis, and adaptation based on the research findings.
\end{abstract}

\section{Introduction}

A

new economy dominated by the electronic culture is rapidly overtaking both the business and the educational cultures. With the Internet, "We are in a new 24-hour day society, where you can do round-the-clock banking, shopping, and studying" (Joseph Hankin, 1999). This change affects the employability of the labor force and the educational skills needed for the e-culture: "The New Economy is at once ripe with mergers and rampant with new-business failures, with downsizing and labor shortages, with an insecure and transient labor force (Kevin Dobbs, 2000). The boom distance education reflects a change in "marketplace demographics" (Worley, 2000). The rise of the information age has intensified the need for employees with new skills, affecting the ability of the educational establishment to respond. As Khirallah explains, "With business moving at high speed, companies face a tough training challenge: keeping employees up to date on the latest technologies and business practices" (2000, p. 22).

For the education sector, "The entire e-learning market is evolving quickly" (Aldrich, 2000). Some confusion stems from the conflicting terminology: "we have several names for essentially the same thing-for example, " distance education,' 'distance learning,' and 'distributed learning'-while we sometimes use one term, such as 'virtual university,' to refer to very different types of educational arrangements" (Wolfe and Johnstone, 2001). Initial statistics indicate "an estimated 1,661,100 enrollments in all distance education courses, with most of these at the undergraduate level" (Heller Report, 2001). The rapid rise in distance education has lead some theorists into "confidently predicting the end of the university" (Neal, 2001). For example, Peter Druker is quoted as saying, "The future is outside the traditional campus, outside the traditional classroom. Distance learning is coming on fast" (Gubernick and Ebeling, 2001). However, the evidence does not point that clearly toward the demise of traditional education. For instance, the development of Internet 2 as having great potential for networked undergraduates (Basch, 2001); and anecdotal evidence points toward a preference for traditional modes of delivery, particularly at the undergraduate level where "'brick" is preferable to "click" (Dyrud, 2001).

The educational community must creatively customize this new environment. This paper urges both the administrators and faculty from all disciplines to comprehensively view distance education: to recognize the need, to

Readers with comments or questions are encouraged to contact the authors via email. 
recognize the opportunity, and to adapt to this distinctive environment. To fulfill this objective, we will present a communication model that identifies the elements of the process, then use this model to outline a five-step process. Specifically, the paper will address the following topics:

The Process Model for Program Analysis:

Step 1. Inputs - Identify Resources and Assumptions

Step 2. Purpose - Determine Objectives, Identify Audiences

Step 3. Method - Select the Medium and the Process

Step 4. Implementation - Conduct the Program

Step 5. Feedback — Follow up, Interpret, Adapt

\section{The Process Model For Program Analysis}

Our approach to distance education follows the elements described in the Process Model for Program Analysis (see Figure 1). The steps in this process adapt the elements of the Rhetorical Process Model of Communication (Beck, 1999, p. 42). This model considers programs from a systems perspective: Resources -> Purpose \& Method -> Implementation -> Feedback. The division between purpose and method represent the objective and subjective dimensions of the program.

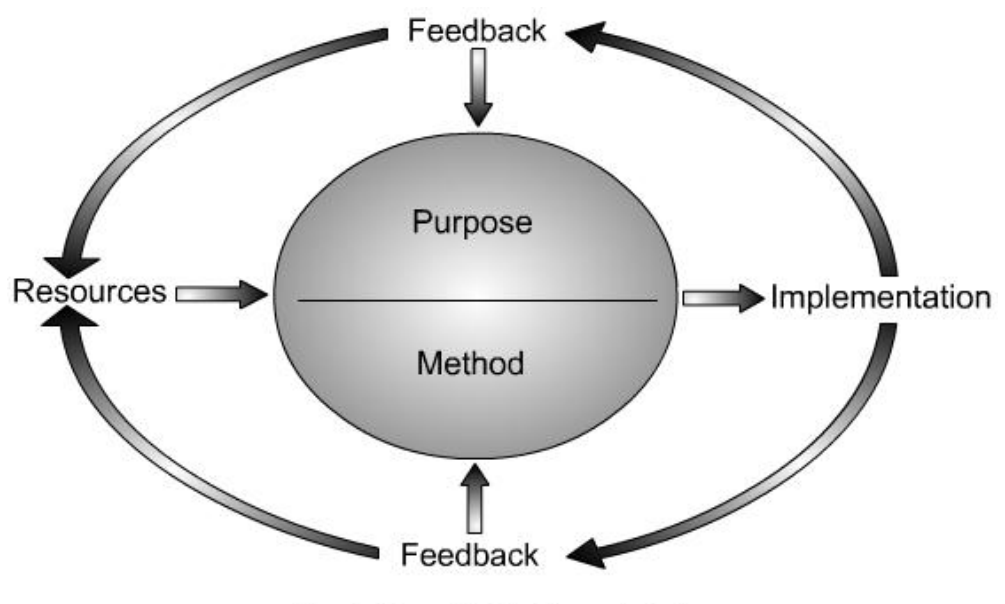

Figure 1. Process Model for Program Analysis

For any process, the expectations encompass both the objectives and the audiences involved. The method consists of the media used, along with the process used to create and sequence the flow. In this model, the output consists of the implementation of the process, including the product and its interpretation. Ultimately, the feedback loop enables the initiator to evaluate how well the process matches the original expectations.

\section{Step 1. Inputs -Identify Resources and Assumptions}

Before any organization begins a new program, it must identify the available resources it can commit to the program. Resources include items already on hand or those easily acquired. Although tangible items are easier to identify, the organization must clarify the more subtle input resources, its assumptions. These include external assessment of the wider business environment, and internal assessment of the organization's culture. For educational programs, culture includes the educational philosophy of the faculty and staff, plus their entrepreneurial spirit for beginning new programs. 


\section{Identify Resources}

In the late 1990's most colleges in the United States rapidly developed courses, and even complete degree programs, delivered by the school and completed by the student "using the Internet as the primary communication vehicle" (Lee, 1998). In general, institutions expected that IT would save money for higher education (Boettcher, 2000). By 2000, 58\% of public two-year institutions were offering distance learning courses (Bower, 2000). Among the four-year institutions, involvement depended on the institution's size: " $87 \%$ of those with more than 10,000 students offered distance classes, while only $19 \%$ of institutions with fewer than 3,000 students did so" (Svetcov, 2000). Most discussions focus on the extent of participation in distance education.

Distance education needs significant resources. "The cost structure of distance education systems differs considerably from that of traditional systems. Investment and fixed costs are higher and operating costs are generally lower" (Boettcher, 2000). Institutions may consider the trade off from traditional instruction: "In general, instructor-led classroom training is expensive, often costing thousands of dollars plus the price of travel" (Orubeonodo, 2001). Administrators may believe the distance education merely involves taking existing readings, exercises, handouts, and posting them to the Web. Such an approach, while cost-effective, is not medium effective. Success requires creating new "courseware" representing a significant capital expense (Goldstein, Change 2000). Beyond course development, further support includes equipment, support personnel, and training: "Support for faculty and staff is not limited to money and technical support, but must also include support for training, released time, acknowledgment of intellectual property rights, and academic credibility for tenure and promotion" (West, 1999).

\section{Identify the Assumptions}

As they strive to develop distance programs, educators must clarify the assumptions among the administration, the faculty, and the staff. By their very nature, assumptions represent the unexamined "givens" for the institution; but effective program implementation involves making these assumptions explicit, particularly the underlying motives for the involvement: "Are colleges and universities drawn to distance education because they believe it will deepen and extend the learning experiences of students, or are they just trying to get a piece of the dot-com action?" (Weigel, 2000). Lee identifies some of these conflicting perspectives on distance education:

- Distance learning is a new and universally desirable phenomenon.

- Distance learning will totally supplant campus-based learning in the future.

- Distance-learning methods are ineffective for most university-level learning goals.

- Distance-learning experiences are inferior to campus-based learning experiences. (1998)

Ultimately, acceptance of distance education requires that institutional stakeholders overcome ingrained attitudes. "Online learning does not replace or minimize the importance of teachers or trainers, but rather removes the physical constraints of buildings and distance, thereby expanding the teacher's potential reach, efficiency and effectiveness" (Stoll, 2001). Some organizations may simplistically believe that merely adding computers will solve any communication problem. For example, "Online courses and degree programs open up higher ed to anyone with access to a computer and a modem" placing the "tools for obtaining a well-rounded education literally at the fingertips of anyone with Internet access" (Thomas, 1999); "You can now find the online equivalent of almost any brickand-mortar learning environment"(Mangis, 1999). But as Greengard observes, "you can put information at people's fingertips, but you can't force them to use it effectively" (2000).

Not all institutions adapt to distance education "cheerfully and quickly"; among the reasons, "the greatest deterrents seem to be the faculty, the costs, and the reluctance to change their perception of themselves as the "only show in town" as purveyors of knowledge" (West, 1999). On the practical level, shifting to distance requires training people on equipment so they can use it effectively. Such training involves a significant change in attitudes. Patterson believes that becoming effective with an electronic medium means overcoming FUD: "fear, uncertainty, and doubt" (2000). In particular, institutions must address how to "support faculty who worry about how to teach and learn in these new environments with these new tools" (Boettcher, 2000). Businesses leaders and educators must take the forefront in helping employees, clients, and customers overcome these initial attitudes. From the student 
perspective, a shift to distance means more responsibility of the student for his or her education. "Learners need to develop personal learning contracts, targeting their own objectives for training rather than the instructional objectives of the course" (Maise, 1999).

\section{Step 2. Purpose - Determine Objectives, Identify Audiences}

The distance education process creates a high level of expectation, but it requires focus. The institution must clarify its own objectives, which may involve mixed motives, educationally and financially. In addition, it must understand the various audiences for the distance process.

\section{Determine Objectives}

Many academic institutions consider "the prospect of increased revenue from distance education" as a significant factor in offering distance courses (Wolpert, 1998); however, planning for such an endeavor must consider "the intent of both pedagogical and financial success" (Robinson, 2002). Financial considerations tend to influence the selection of level of courses; according to the Heller report, institutions offer for-credit distance education courses more at the undergraduate than at the graduate/first-professional level (2000). Although distance education focuses on both traditional and non-traditional student audiences, it usually attracts more of the non-traditional adult learner. Effective programs thus can benefit by creating a vision of adult development, accommodating "the special social, psychological, and political characteristics of adult learning" (Russell, 1999). To confront the significant conflicts in the objectives for a distance program, universities must ask themselves some probing questions, as outlined by Newman (2000):

- Is our purpose to encourage intellectual development so that students may enjoy the life of the mind, or is there a practical purpose for such development that benefits society? Why, in other words, should society be interested?

- Will the same modes of socialization to the life of the mind work for an ever-broadening share of each age group of students?

- Which of these activities make an impact and which are cheerfully ignored by the students?

As these questions tend to clarify the market niche for the distance program, they may seem to focus only the financial objectives of a program. However, this process implies that distance programs are tapping into a different group of students than the traditional target audience.

\section{Identify Audiences}

Whether or not an institution considers potential students a "market" or not, educators must understand the audiences for their programs. One audience consists of employers, for whom "Online learning holds tremendous potential to better deliver continuing education and training to those already in the workforce, thereby boosting their knowledge and productivity" (Thomas, 1999). Employers use such training based on its cost effectiveness: in addition to being less expensive than outside training, employers can offer employees "the chance to learn at their own pace and from any location (Orubeonodo, 2001), thus giving employees the chance to complete their education while working full-time (Klor De Alva, 1999). This group, one of the fastest growing markets in higher education, needs institutions that can "design flexible, customized programs to meet their education needs and lifestyles" (Worley, 2000). According to West, "The growing college population are adult students over the age of 25 who are non-residential, working full-time, perhaps with a family from diverse backgrounds" (1999).

Williams identifies the potential audiences for education in general, including the subset of distance education. Three models describe the student's role in learning: the student-as-product, the student-as-worker, studentas-consumer (Williams, 2001).

Student-as-product. This model emphasizes work in the classroom, tending to employ mostly lec- 
tures and discussions to deliver information to the student.

Student-as-worker. As learning mechanisms, this model employs inquiry, activity, and discovery strategies that emphasize exercises and projects, with students working either individually or in groups.

Student-as-consumer. This model is particularly popular among higher education administrators: sales of a particular product (i.e., credit hours generated) serve as the simplest way to manage budgets; and student enrollment and classroom evaluations provide the simplest way to evaluate faculty performance.

Both the student-as-product and the student-as-consumer models are instructor-centered (Williams, 2001). In fact, some skeptics see computer-based courses as "thinly veiled field trials for product and market development," in which students "are studying their courses" while "their courses are studying them" (Noble, 1998).

But educators must delve deeper into their audiences. For instance, because of the socio-economic background of potential students, schools may need to train their students to use computers and the Internet as educational tools when many students arrive on campus without having prior exposure (Roach, 1999). And even if they come computer literate, students may lack a sense of self-direction and conscientiousness in completing assignments (Neal, 1999). One insightful article describes this process with an intriguing subtitle: "Why the e-Learning Revolution Is Not about Computers: It's about Communication." In this roundtable discussion, Jaron Lanier describes the impact from the corporate viewpoint: "when they really begin gathering the data, they'll see that putting the effective use of real people first actually saves money. More learning happens more quickly, and it's of higher quality" (2000, p. 69). Institutions can construct learner profiles, containing "data about their educational history and learning preferences, allowing for personalization of course materials and programs-this will put the learner in charge of the educational process (Johnstone, 2002). The focus on the purpose of distance education, both in the objectives and in the audiences, has significant implications both for the educator and the business audiences.

\section{Step 3. Method — Select the Medium and the Process}

Historically, the concept of methodology has a strong association with education. The process model, however, uses the term method to encompass the medium used to convey ideas, and the process used to put them together. Purpose and method thus interact to create the output of the system.

\section{Select the Medium}

While the medium plays a role in all education - from simplistic "visual aids" to complex video productions - the medium takes center stage with most discussion for distance education. In one study, "a technology strategy will need its own special funding." (Finkelstein et al., 2000). Our discussion here begins with the requirements for distance media, then focuses on the medium as educational tool. Overall, media use requires equipment, maintenance, and training for the educators. When not used effectively, media intending to enhance and implement education may in fact become detrimental.

Media as requirement. Along with its potential, on-line education brings new requirements involving resources and accessibility. According to Khirallah, online classes require extra bandwidth which works on in-house ethernet lines but not on traditional phone lines. Technology may bring increasing potential, yet full implementation must ensure expanding access to the technology (2000, p. 22). For example, at current speeds, the Library of Congress' entire collection of books could be transmitted in just over five minutes (Hankin, 1999); however, not every potential user has the equipment to handle such a download in that amount of time. Ultimately, the Internet' s potential is not automatic; rather, it requires resources for users, along with updated trainers who can teach users how to harness this resource as a major endeavor. Nor are the techology requirements limited to an adacemic discipline and the computer center. Academic libraries must also adapt to the needs of learners, particularly adult learners, "Driven by economics and enabled by innovations in educational technology, this new market presents significant 
marketing challenges to academic libraries" (Wolpert, 1998). Some even suggest a greater role for libraries in "raising the adult learner's awareness of the potential rewards to be gained with a little patience and a personal computer" (Niemi et al., 1998).

Media as educational Tool. To expand the ways people learn in our Information Age, institutions increasingly turn to Internet-based education and to virtual classrooms. For some thinkers, such a change represents a minor adjustment: "a virtual classroom is not a special form of distance learning environment, but just another form of classroom" (Williams, 2001). Internet-based programs become attractive as a way to meet diverse needs with flexibility. Further, the increasing use of the Internet has brought adaptation in traditional distance-education formats, especially based on the type of institution. For instance, two-way interactive video was more likely to be used by public 4-year institutions than by any other type of institution (Heller Report, 2000). In using the full potential of distance media, educators can select modalities to fit the need of the user. Using Internet programs "has the potential to revolutionize the way people learn - not only in terms of the medium used, but by making continuing education a life-long activity" (Robb, 2000). Proponents of virtual universities point out that networked computing permits us to replicate the classroom experience by creating "virtual groups" of students (Neal, 1999). Also teachers can efficiently reach all students through general e-mail answers to common questions (Wang and New lin, 2001). The virtual classroom can bring out the Internet' $\mathrm{s}$ full potential by including diagnostic tutorials, voice-overs, animated graphics, online text and a tutor who can be contacted (Stoll, 2001). According to David Frabotta, "The virtual classroom is more than a buzzword. It represents a classroom furnished with the Internet, e-mail, digital cameras, instant messaging and videoconferencing, enabling students to talk to professors, instructors, industry experts and other students from anywhere in the world using audio and visual components" (2000).

Media as requiring additional resources. Media for distance education creates further resource needs. "Technology support requirements in higher education are escalating, but the resources available to meet these needs are not" (U.S. Distance learning). "Design and production costs for audio-visual education programs are generally much higher than the costs of transmissions and reception" (Boettcher, 2000). Distance programs also require creative ways of adapting the extensive library resources: "With the possible exception of networked databases, nearly every traditional product and service offered by academic libraries is incompatible with educating at a distance" (Wolpert, 1998). And costs go beyond the hardware alone, since resources include intensive training for educators using the systems and technicians who maintain them. Table 1 identifies the required resources for distance education.

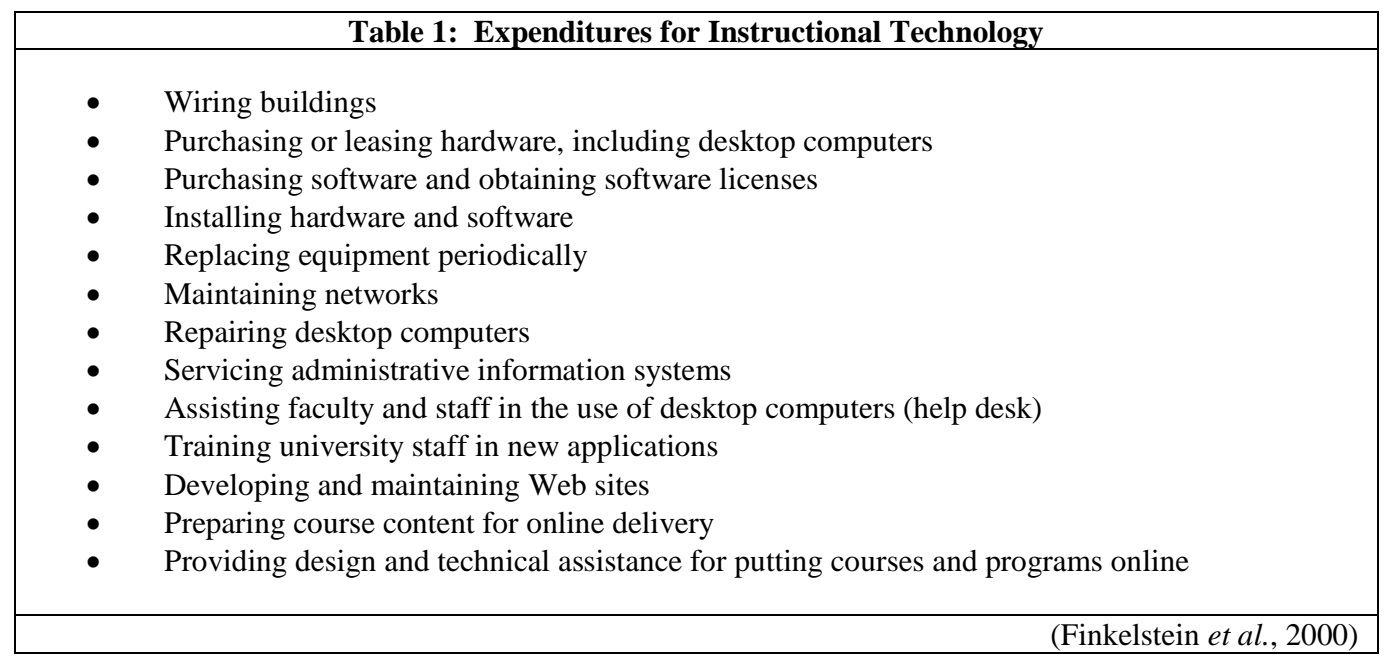

Resources affect students as well, even for those involved in the more traditional forms of higher education. 
Since 1998, some major universities have "made mandatory the use of computer telecommunications technology in the delivery of higher education" (Noble, 1998). Yet technology continues to evolve, particularly with the development of Internet 2: "The technology advances envisioned under Internet 2 are expected to filter rapidly out to the wider Internet community" (Basch, 1997).

Media as a potential negative. Distance education has the potential to foster anonymity. "In the virtual classroom, instructors are recognized solely by the fact that their screen names are different from their students' (Wang and Newlin, 2001). While such an arrangement may create a non-intimidating environment with a level playing field, it may also create role playing and gamesmanship with the student (Wang and Newlin, 2001). High tech remedies may solve some issues while compounding the problem (Noble, 1998). And a focus on the media may change the role from educator to technology coordinator:

The teacher becomes, in many settings, a multi-media coordinator, for other delivery systems will be in use: videodisk, videotext, audio and videocassette recorders, telephone, videophone, radio, newspaper, closed circuit television, open broadcast television, learning packages including print and non-print materials, home computers, two-way interactive classrooms [Hankin, 1999].

\section{Select the Process}

The process of program development involves the sequence of ideas, types of examples, and word choice. The educator prepares for multiple repetitions to reinforce concepts, including previews, presentations, and reviews. When presenting an abstract concept, the educator needs to build up to complex ideas through the simple, and to bring ideas to life with examples, metaphors, and analogies. The amount of variety in approaches will appeal to the multiple learning styles in the audience. The "one-text/one-test/one-delivery-mode-fits-all" approach to instruction is becoming less and less appealing (West, 1999). According to some educators, "a well-designed face-to-face course includes all of the positive aspects of a well-designed online course (e.g., interactivity among students, access to external sources of information)." However, those who rely on lecture tend to dampen, not promote, interactivity among students, since the "norms of face-to-face classroom militate against more active participation by students in the educational process" (Cini, 1998). For distance educators, the aim is to reproduce the functionality and the "look and feel" of the classroom in a new operating environment (Weigel, 2000). Part of the feel is the sense of camaraderie and belonging among class members. "To foster the development of the online class as a learning team, students should be encouraged to assist one another when they confront obstacles rather than encouraged to ask the instructor for help" (Cini, 1998).

With the target audience of non-traditional students, most distance education programs want to provide meaningful learning for adults. This means creating instruction based on an authentic model of adult learning and development. Constructing such a model would build on four general principles:

- plan for learning across the lifespan;

- identify the distinctive characteristics of adult learners,

- emphasize the goals of adults,

- create adult-situated contexts for learning (Stites, 1998).

An adult-focused model would also incorporate an inquiry-based curriculum, whose objectives include life skills as well as "basic" ones, performance-measured outcomes, and a learner-centered locus of control (Russell, 1998). Within these adult-focused principles, educators would do well to follow the Seven Principles for Good Practice in Undergraduate Education as published by the American Association for Higher Education (Merisotis and Phipps, 1999):

- encourage contacts between students and faculty; 
- develop reciprocity and cooperation among students;

- use active learning techniques;

- give prompt feedback;

- emphasize time-on-task;

- communicate high expectations; and

- respect diverse talents and ways of learning.

Ultimately, faculty and administrators must create the mix of technology and process that comprise the method of distance education: "The expense of creating highly interactive and pedagogically rich content is another challenge" (Johnstone, 2002).

\section{Step 4. Implementation - Conduct the Program}

After completing all the planning, institutions offer their programs and conduct the courses. Since this phenomenon is relatively new, hard data is limited. Few institutions have surveyed to determine "what increases in institutional budgets relate to IT" (Boettcher, 2000). One trend indicates more for-credit offerings at the undergraduate than at the graduate/first-professional level (Heller Report, 2000). Others see the changes as less a function of technology and more a reconceptualization of the entire enterprise of postsecondary education," with an apparent motto of "Education -- anytime, anywhere, at reasonable rates" (Neal, 1999). The various types of educational delivery entail different costs. Table 2 estimates the hours expended through differing media to produce one hour of student learning.

\begin{tabular}{|lc|}
\hline \multicolumn{2}{|c|}{ Table 2: Academic Work to Produce One Hour of Student Learning } \\
\hline & \\
Instruction Medium & Hours of academic effort \\
& \\
Lecturing & $2-10$ \\
Small group teaching & $1-10$ \\
Videotaped lectures & $3-10$ \\
Teaching text (i.e., book) & $50-100^{*}$ \\
Broadcasttelevision & $100^{*}$ \\
Computer-aided learning & $200^{*}$ \\
Interactive video & $300^{*}$ \\
\hline & \\
\hline
\end{tabular}

Focusing more closely on the cost of a distance course, Boettcher estimates "the cost of developing a fully standalone three-credit course to be delivered independent of an experienced faculty member can range between $\$ 100,000$ and $\$ 400,000 "$ (2000). Boettcher refines the costs further, considering a range from courses delivered 100 percent on the Internet to courses enhanced by use of the internet. Table 3 estimates these total costs.

Table3: Estimated Costs of Providing a Web Course 


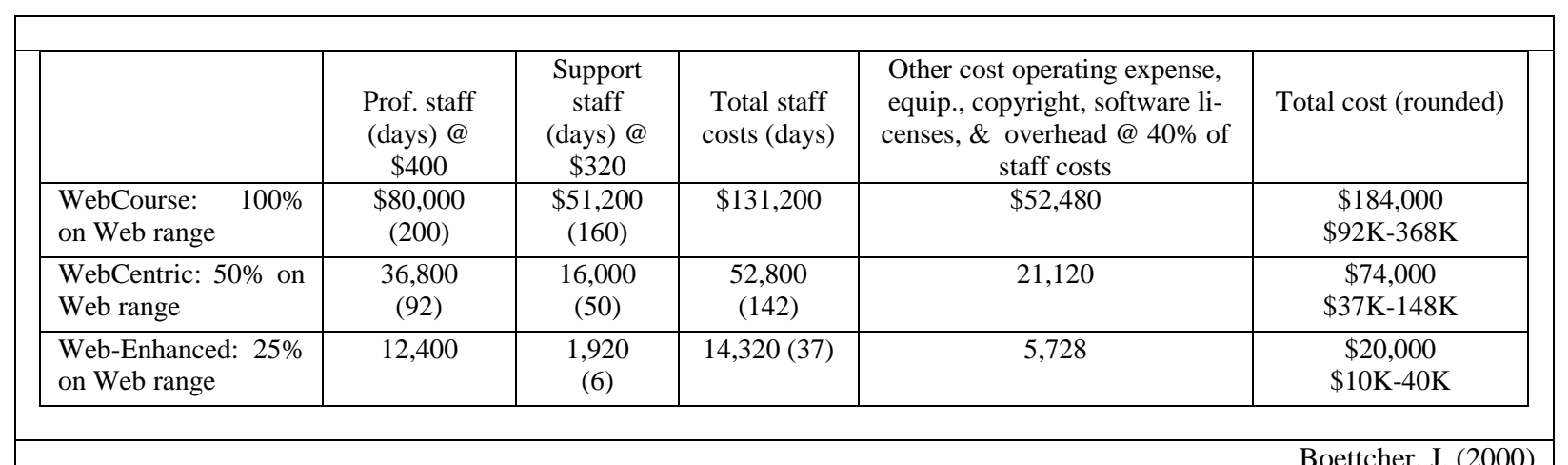

Aside from the numbers and income impact among the institutions, the changes for faculty prove the most significant. "Faculty regularly self-report working 60 to 80 hours a week while making the transition from classroom to Web materials" (Boettcher, 2000). Faculty must adapt to using e-mail efficiently; otherwise, an unsuspecting faculty member finds him- or herself "spending all day doing nothing but reading and responding to e-mail messages" (Dyrud, 2000). Some faculty face difficulties in shifting to a conceptual model of student-as-consumer or studentas-worker. Left with a traditional student-as-product model, faculty may "find that teaching in a virtual classroom is both unappealing and difficult because it will represent a radically different approach to education from the one to which they are accustomed" (Williams, 2000). Along with the changed approach to students comes the changed view of delivering a course, where the new distance educator becomes "a manager of resources" (Wolpert, 1998). But Goldsteing provides a more intriguing metaphor to define the faculty role in the "creation" of courseware as that of a playwright:

Although in the classroom the professor is truly a one-person show, the faculty role in the evolving world of technology-mediated courseware is rather more like that of a playwright, whose work is supported and brought to life through a team of instructional designers, technology specialists, and computer experts (Goldstein, 2000).

\section{Step 5. Feedback — Follow up, Interpret, Adapt}

Though often overlooked, feedback is central to any systems process. Too often people assume that communication occurs when some message is sent-spoken-written-broadcast. While machine transmissions can be verified, human communication must recognize that "Communication refers to the message perceived rather than to the message sent in an organization" (Beck, 1999, p. 3). Unless we know the message that receivers perceive and interpret, we have no sense of what transpired. As a communication-based process, education must also examine the feedback to understand how the process worked. As Stephen Manes explains, in the age of e-mail, "E-mail often causes problems that the sender is the last to know about" (Manes, 1996, p. 39). For distance education, feedback includes follow-up on the process, interpretation of the data, and adaptation based on the results.

\section{Follow-up}

A new world of distance education demands new thinking. How the process is designed, delivered, integrated, and supported are key components to a feedback system. The meaningful transition to e-education has just begun. To determine measures of effectiveness and efficiency requires innovations in social and political thought, even more than mere technology. The educational process requires feedback from the professor, from the student, and from the wider community, especially businesses who hire (and more importantly, fund) graduates. These stakeholders should expect to become involved in continuous feedback.

The forgotten component begins with the student, people whom educators often tend to overlook. In the "Virtual Roundtable," Dick Schaff comments to Schank that "You've suggested that educators have not traditionally 
looked for feedback from the learner." Schank responds, "That's exactly right, because they don't give a damn about students." But as Schank continues, "The online format gives trainers flexibility, but it also enables users or students to vote with their feet, easily taking classes at another school. In the feedback process, students should be asked to reflect on their experience, to objectively look back, starting with feelings about the experience but progressing to a cognitive analysis" (2000).

More than the educator and the student, feedback involves the wider community as well. As Mary Furlong states, "To me, the elixir is not the technology. It's the knowledge base of our community members that is shared through the technology that's the most important" (2000). Follow up from this wider community is still preliminary, but a synthesis of recent research in Education identifies some of the shortcomings and obstacles of embracing the Internet in higher education settings: poor/limited interactions, technological difficulties, software limitations, and increased time commitment. Overall, however, the survey finds that "some of the concerns noted in prior investigations about Internet-based instruction have not been supported by the extant literature" (Piotrwwski \& Vodanovich, 2000). The discussion below focuses on the issues involved in interpreting the current results and issues to resolve in adapting the process.

\section{Interpret}

Interpreting the results of the distance education involves many perspectives. Our summary of research focuses on the student, the faculty, the institution, and the potential negative influence on learning.

Student. Student feedback on distance education begins with practicality. "Students were taking distance learning courses for their convenience in helping them cope with the demands of busy schedules and to meet the requirements of their programs of study" (Bower, 2000). Research on student response often focus primarily on the technology involved; however, the "results seem to indicate that technology is not nearly as important as other factors, such as learning tasks, learner characteristics, student motivation, and the instructor" (Merisotis \& Phipps, 1999). Through use of student chat rooms and instructor feedback through e-mail, "most university graduates would likely agree that such opportunities for discussion were among some of their most meaningful educational experiences" (Lee, 1998). "Interactive messaging, instant messaging, and peer-to-peer communications technologies will extend the reach of the learning experience" (Johnstone, 2002). Students even recognize the benefit of paying a premium for the educational opportunity. "For students, IT will involve some additional costs in the form of technology fees, the purchase of computer equipment, or tuition increases spurred by institutional investments in IT" (Boettcher, 2000). According to one report, students willingly "pay a premium for the convenience of the remote access and the prestige of a Duke degree $\$ 82,500$ (frequently picked up by students' employers), compared with $\$ 50,000$ for the regular on-campus M.B.A." As a result, "If education is the goal, cyberstudents get that at a fraction of the cost of attending a traditional Ivy League college" (Gubernick \& Ebling, 1997).

Faculty. Despite fears to the contrary, experience with distance education indicates that "technology cannot replace the human factor in higher education." (Merisotis \& Phipps, 1999). Faculty themselves need to internalize this finding; otherwise, "thery may believe that their students can gather all the course information they need simply by accessing the links on the course Web site" (Wang, 2000). "For faculty, the implications are enormous. In the short term, tremendous stresses and pressures will be associated with increased workload" (Boettcher, 2000). Because faculty are still adapting to this new medium, they still rely largely on their original approaches, with minimal adaptation: "All the available data seems to indicate that online courses and programs are proliferating steadily. Yet they are, by and large, still quite faculty-centered and adhere to the traditional 'one size fits all' model of pedagogy" (US Distance). As they immerse themselves into the new medium, faculty will begin to change their approaches to take advantage of the power of the medium. With this change, administrators do not appear to recognize the workload impact of teaching distance courses. "Administrators apparently assume that faculty can teach distance classes on top of a full teaching load, that these classes are somehow easier than traditional courses" (Dryud, 2000).

Institution. Institutions often enter the distance education market for hopes of increased income and for a "fear of getting left behind" in the "incessant pressures of "progress"'(Noble, 1998). Distance programs frequently 
must become self sufficient within the institution: "In the zero-sum world that typically characterizes collegiate finances, the opportunity to secure capital without depleting other resources can seem very attractive. Couple that need with a financial marketplace that describes e-learning as the 'next killer app on the Internet' and the new venture looks particularly appealing" (Goldstein, 2000). To succeed, "the key is to take online materials developed for one audience and then repurpose them into different sized offerings and into different markets" (Robinson, 2002). With limited resources, institutions often coerce faculty, especially by "placing the greatest pressures on the most vulnerable -- untenured and part-time faculty, and entry-level and prospective employees" (Noble, 1998). Despite the financial push to save expenses, distance programs actually incur additional costs. "Each course has to have an instructor, a graduate assistant, technical people to be there in case the connection breaks down, as well as someone to design the course" (Mangan, 2002). Rather ironically, the professionals in the education process become reduced to traditional labor meeting organizational needs. "Teachers as labor are drawn into a production process designed for the efficient creation of instructional commodities, and hence become subject to all the pressures that have befallen production workers in other industries undergoing rapid technological transformation from above" (Noble, 1998). As institutions face the implications of the cost of distance programs, they must react. At one level, "many traditional institutions will feel compelled to narrow their focus and to lose their historic functions" (Newman, 2000). At the other, institutions may withdraw from their distance programs: at SUNY Buffalo, "the business school joins a growing list of institutions that have concluded that online programs aren't worth the expense and hassle" (Mangan, 2002). In broad terms, "While colleges and universities have been spending enormously and increasingly on IT, we as yet have no clear benchmarks of what the costs of IT in teaching and learning are." (Finkelstein et al., 2000)

Negative Impact on Learning. In interpreting the feedback concerning distance programs, we must recognize the negative aspect of distance programs. To begin with, distance programs may not provide any specific advantage in either productivity or learning. "Recent surveys of the instructional use of information technology in higher education clearly indicate that there have been no significant gains in either productivity improvement or pedagogical enhancement" (Noble, 1998). For many students, the impact of the instructor becomes a negative in the learning process, in terms of impact and awareness of students: "the instructor did not come across as well as in person, did not seem to be as enthusiastic, and was not as aware of students not grasping the material" (Dyrud, 2000).

Among the learning aspects of distance education, students appear to master cognitive areas without concurrent learning of affective dimensions: "it is difficult to find evidence that students are learning tolerance and acceptance of others, learning to entertain opposing views without reacting defensively, or learning to examine seriously the sources of their attitudes, beliefs, and values." Additionally, students face different interactions: "In short, it is too easy, in an electronic environment, for students to escape the confrontations, challenges, and learning opportunities that are present in the classroom" (Neal, 1998). These learning limitations relate to two significant findings, the isolation of students and subsequent drop-out rates" "Another consequence of electronic communication is, ironically, increased isolation.... withdrawal rates in distance classes are significantly higher than those of traditional courses, in some cases approaching 60\% (Dyrud, 2000). Institutions may fail to address "the fact that distance learners have higher drop-out rates than other students" (Worley, 2000). One sceptic even concludes that "The fact is, much of what passes for online education today would put most of us to sleep" (Svetcov, 2000).

\section{Adapt}

Feedback is not an end in itself, but a means to determine how to change in the future. In examining current findings, issues in adapting programs seem to fall into three areas: conceptual concerns, cost-benefit analysis, and systems dilemmas.

Conceptual Concerns. At a basic level, "research on distance education does not include a theoretical or conceptual framework" (Worley, 2000). As a result, the discussion in the professional literature involves individual experiences rather than more wide-spread patterns. The conceptual discussion to date often compares distance education with traditional classroom. Williams identifies the frequently asked questions in this discussion:

- whether Web-based courses have the same rigor as traditional classroom courses, 
- whether there is a high probability of students cheating in Web-based courses,

- whether students enroll in such courses simply to select the easiest one they can find, and

- whether Web-based courses enforce radically different and perhaps limiting styles of instruction (Williams, 2001).

A different approach to such questions comes from Worley:

research that attempts to compare technology-based teaching methods with "traditional" methods is not asking the right question. Such research assumes that traditional teaching methods are somehow a uniformly successful and proven standard against which to measure success in nontraditional classrooms [Worley, 2000].

This dialogue reflects the need to address theoretical bases for evaluating distance programs.

Cost Benefit Analysis. Cost obviously becomes a major concern in the ultimate analysis of distance programs, but cost must be weighed in light of educational benefit. "It has been difficult to obtain hard evidence on the costs and benefits of IT-based teaching learning. The benefits tend to be educational and long-term and there is no consensus on the methodology of measuring them" (Boucher, 1998). Because of a lack of consensus on methodology, "Correlation between cost and effectiveness is not exact. Costs depend on institutional variables, such as mission, information technology infrastructure, course design, student audience, and faculty and student characteristics" In addition, costing studies must consider a wide range of factors: "the quality of the output, the exact specification of the technology employed, the working practices used" (Boettcher, 2000). In absolute terms, making money depends on economies of scale. In comparing types of delivery, "Distance education costs less than classroom teaching when we are dealing with a large number of students taking a particular course" (Finkelstein et al., 2000). But economies of scale also depends on the institution's size: "The most cost-effective distance leaning institutions have been the dozen or so mega-universities, with their students numbering 100,000 or more" (Finkelstein et al., 2000). Ultimately, institutions must balance opportunity with financial costs, both short- and long-term:

The system is likely to encompass all sorts of variations and mixtures. The opportunities are, as a result, stunning in their scope. The real threat to higher education is that it will focus only on the short-term gain that these new forces offer, that we will search for ways to maximize revenue at the expense of the longer-term purposes that have formed the backbone of higher education for centuries (Newman, 2000).

Systems Dilemmas System-related issues involve both the internal dynamics within a given institution and the wider system of education of which the institution is just one part. Bates sees the interrelationship between technology, costs, and the learning environment:

It is wrong to assume that technology can simply replace labor and thereby reduce educational costs. Applying technology in teaching and learning cannot reduce labor costs without reducing the quality of learning. Learning materials can go only so far as a substitute for the interaction between a learner and a real teacher [Newman, 2000].

Since faculty form the focus of an institution's involvement, a change to distance learning creates significant change for the faculty role: "As currently configured, faculty fulfill many complex and demanding roles developing instructional materials, designing courses, managing" (Worley, 2000). But the role of faculty in course development raises long-term issues of job security: "once the faculty convert their courses to courseware, their services are, in the long run, no longer required" (Noble, 1998). The institution faces other internal system-related issues as identified in Table 4 .

Table 4: Factors that Hinder Educational Change

- $\quad$ limited availability of equipment

- lack of faculty training

- no clear expectation that faculty will incorporate technology into academic activities 


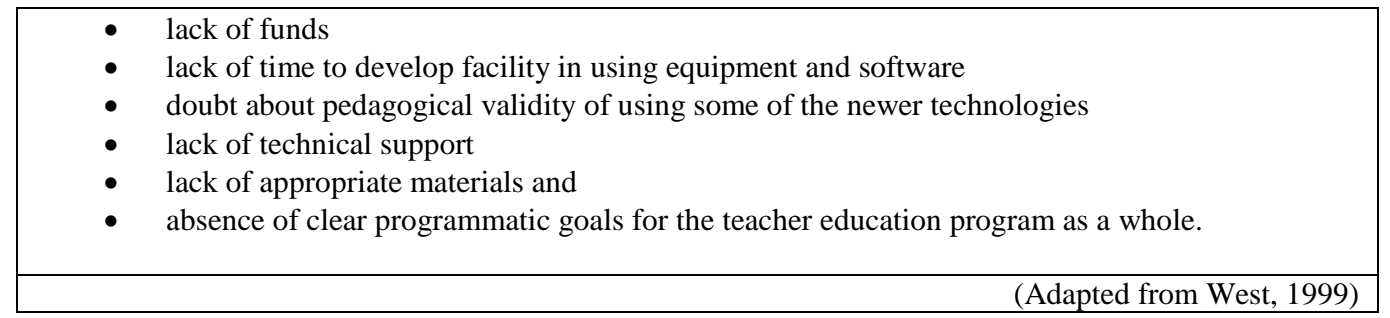

Aside from the internal factors, educators must face the external system educational system. The general population changes create the need for institutional change: "As people are interacting more and more online, it's important to consider how best to provide that capability and create communities of interest online" (Johnstone, 2002). But as institutions add distance components, they must also maintain accreditation requirements: "Among the establishment's most powerful weapons is accreditation. Without accreditation schools aren't eligible for federal aid. And, of course, conventional educators control the nation's accrediting bodies for higher education" (Gubernick \& Ebling, 1997). Even the federal government affects institutional involvement through the regulations for financial aid: in 1999, Congress "cautiously expanded federal financial aid to students in such programs," fearing the potential for fraud as experienced previously in correspondence schools (Kessler, 1999).

\section{Conclusion}

A combination of increased technology, of demographic change, and of economic potential has resulted in the rapid expansion of distance education. Within this process, institutions may react too quickly: "Often the wrong questions are asked and answers are hurried" (Kevin Dobbs, 2000). The "right" questions include looking at the systems implication of change, not just the technology.

Getting technology in place and implemented is the easy part -- what is more difficult is to have that technology accepted as part of the fabric of the institution, seeing that all the constituents understand how they can take advantage of it, and finally to find that it is truly delivering for the mission of the institution. [Johnstone, 2002]

Technology provides the means, not the end in the process: "Technological change isn't the most important factor in what the world is going to be like in 25 years." Rather, the significant issue is "how we deal with these policy issues, what values we build into all this, and how peoples of different countries relate to each other are going to be more influential than technological change itself'(Baird, 2000). The answers remain elusive, and the prospect of change leads to intense conflict: "The new environments and tools are causing a clash of expectations and mindsets among faculty, student administrators, and state representatives" (Boettcher, 2000). Yet the potential raises excitement and possibility:

I'm really a hard-core humanist. I very strongly believe that we have a duty to ourselves not to allow ourselves to be reduced by any of our own ideas, not to allow ourselves to be confined by some system of thought, whether we do it using a computer or anything else. I believe we have potential that we can't know about, and the only way we can discover our unknown potential is to not box ourselves in [Lanier, 2000].

\section{References}

1. “A Virtual Roundtable: Why the e-Learning Revolution Is Not about Computers; it's about Communication." Training, September, 2000, p.74.

2. Aldrich, Clark. "Customer-Focused E-Learning: The Drivers.” Training and Development, 54:8 (Aug, 2000) $34+$. 
3. Baird, Zoe. "Technological change isn't the most important factor in what the world is going to look like in 25 years." Fortune, Oct 9, 2000, p. 269.

4. $\quad$ Basch, Reva “The next net." Computer Life, Sept 1997 v4 n9 p 48(2).

5. Beck, Charles. Managerial Communication. Upper Saddle River, NJ: Prentice-Hall, 1999.

6. Biggs, Maggie. "Enterprise Toolbox: Businesses Will Need to Leap Two Hurdles to Achieve Success with ESignatures.” InfoWorld, 22:29 (Jul 17, 2000) 74.

7. Boettcher, Judith. (2000). How Much Does It Cost to Put a Course Online? It All Depends. In M. Finkelstein \& et al. (Eds.), Dollars, Distance, and Education (pp. 172-197). Oryx Press.

8. $\quad$ Boettcher, Judith. "The Changing Landscape of Distance Education.” Syllabus, July 2002 v15 i12 p22.

9. Bower, Beverly L. "Community College Student Satisfaction with the Online and Teleclass Experience." Academic Exchange Quarterly, summer 2000 v4 i2 p54.

10. Cini, Marie A "Learning Leadership Online: A Synergy of the Medium and the Message." Journal of Leadership Studies 5:2 (Spr 1998) 103+.

11. Dobbs, Kevin. "What the Online World Needs Now: Quality.” Training, September 2000, pp. 84-94.

12. Dryden, Patrick. "Web-olution: Network Administrators Use Intranets for Info Distribution, Remote Troubleshooting." Computerworld, 30:38 (Sep 16, 1997) 57-58.

13. Dyrud, Marilyn A. "The Third Wave: A Position Paper.” Business Communication Quarterly, Sept 2000 v63 i3 p81.

14. Finkelstein, Martin J., et al. (2000). Dollars, Distance, and Online Education. Oryx Press.

15. Frabotta, David. "Continuing Education: Cornell University's Dean-elect Plans to Focus on Research, TechnologyBased Learning." Hotel and Motel Management 215:10 (June 5, 2000) 7.

16. Furlong, Mary, quoted in "A Virtual Roundtable: Why the e-Learning Revolution Is Not about Computers; It's about Communication." Training, September, 2000, pp. 64-76.

17. Goldstein, Michael B. “To Be [For-profit] or Not to be: What Is The Question?” Change 32:5 (Sep 2000) 25.

18. Greengard, Samuel. "Going the Distance.” Workforce, 79:6 (June, 2000) 22.

19. Gubernick, Lisa; Ebeling, Ashlea. "I got my degree through e-mail.” Forbes, 159:12 (June 16, 1997) p84 (6).

20. Hankin, Joseph N. "Alice the College Teacher and the Rottweiler in Wonderland: The Prospects and Problems of Distance Education." Executive Speeches, Oct 1999 v14 i2 p18.

21. Heller Report on Educational Technology Markets, Feb 2000 v11 i4 p9 NCES reports on use of DL in higher ed.

22. Heller, Robert. "First Easy Steps to an E-Strategy." Management Today, June, 2000, p. 34.

23. Johnstone, Sally M. "The Interactive Campus." Syllabus, June 2002 v15 i11 p16.

24. Jossi, Frank. "Online Adventures: The Motivation Factor.” Technology \& Learning 20:9 (Apr 2000$) 32$.

25 .

26.

Kessler, David A.; Keefe, Barbara “Going the distance.” American School \& University, July 1999 v71 i11 p44 (3).

Khirallah, Diane Rezendes. "A New Way to Learn? - As E-commerce accelerates business, companies turn to online learning to cut Teaching Costs." Information Week, May 22, 2000, p. 22.

27. Klor De Alva, Jorge. "Remaking the Academy in the Age of Information." Issues in Science and Technology, winter 1999 v16 i2 p52.

28. Lanier, Jaron, quoted in "A Virtual Roundtable: Why the e-Learning Revolution Is Not about Computers; it's about Communication." Training, September, 2000, pp. 64-76.

29. Lee,Chris. "Vurtual U." Training, August 1998 v35 n8 p81 (1).

30. "Managing Records in E-Mail Systems." Government Finance Review 12:3 (Jun 1996) 64-65.

31. Mangan, Katherine S. "Buffalo Drops Online M.B.A. Program” Sunny, February 20, 2002.

32. Mangis, Carol A. "Back to E-School." PC Magazine (Oct 5, 1999) p. 36.

33. Manes, Stephen. "E-Mail Troubles? You Have No Idea!” PC World, 14:7 (Jul 1996) 39.

34.

35.

36.

37.

38.

Masie, Elliott. “Creating Stickier Online Learning Sites, Classrooms.” Computer Reseller News (Jun 7, 1999) 56.

Merisotis, James P.; Ronald A. Phipps. "What's the difference?” Change, 31:3 (May-June 1999) 12-17.

Neal, Ed. "Distance education" National Forum, winter 1999 v79 i1 p40 (4).

Newman, Frank. "Saving Higher Education's Soul." Change, Sept 2000 v32 i5 p16.

Niemi, John A.; Ehrhard, Barbara J.; Neeley, Lynn. "Off-Campus Library Support for Distance Adult Learners.” Library Trends, summer 1998 v47 i1 p66 (1).

39. Noble, David F. "Digital diploma mills: the automation of higher education." Monthly Review, Feb 1998 v49 n9 p38 (15).

40. Norman, Donald, quoted in "A Virtual Roundtable: Why the e-Learning Revolution Is Not about Computers; it's about Communication." Training, September, 2000, pp. 64-76.

41. Orubeondo, Ana. "Take charge of training.” InfoWorld, April 16, 2001 v23 i16 p100.

42. Patterson, Jennifer C. "Building the Virtual Classroom." Curriculum Administrator, 36:7 (Aug, 2000$)$ p. S14.

43. Piotrowski, Chris; Vodanovich, Stephen J... "Are the Reported Barriers to Internet-based Instruction Warranted? A Synthesis of Recent Research.” Education, fall 2000 v121 i1 p48.

44. Roach, Ronald. "The Higher Education Technology Revolution" Black Issues in Higher Education August 191999 v16i13 p92. 
45. Robb, Drew. “At Home with Internet-Based Training.” Risk Management, 47:7 (Jul, 2000) 27.

46. Robinson, Evan T. "e-Commerce in Distance Education," Syllabus, February 2002, v15, no. 7.

47. Rumble, G. The Costs and Economics of Open and Distance Learning, quoted in Boettcher, J. (2000).

48. Russell, Mary. "Online Learning Communities: Implications for Adult Learning." Adult Learning 10:4 (Sum 1999) 28.

49. Schank, quoted in "A Virtual Roundtable: Why the e-Learning Revolution Is Not about Computers; it's about Communication." Training, September, 2000, pp. 64-76.

50. $\quad$ Stites, Reggie. (1998). Assessing Lifelong Learning Technology (All-Tech). NCAL Report PG98-01.

51. Stoll, John "No Time for Class? Log on to Internet." Automotive News 75:5915 (Feb 5, 2001) 28.

52. Svetcov, Danielle. "The Virtual Classroom Vs. The Real One.” Forbes, Sept 11, 2000 p50.

53. Thomas, Sarah. "Adult Learning Goes Online." Computer Shopper, October 1999 v19 i10 p331.

54. Wang, Alvin Y.; Michael H. Newlin. "Online Lectures: Benefits for the Virtual classroom.” T H E Journal (Technological Horizons In Education), August 2001 v29 i1 p17.

55. Weigel, Van. "E-Learning and the Tradeoff between Richness and Reach in Higher Education." Change, Sept 2000 v32 i5 p10.

56. West, Gail B. "Teaching and Technology in Higher Education: Changes and Challenges" Adult Learning, summer 1999 v10 i4 p16.

57. Williams, Donald. "The Virtual Classroom in Relation to Educational Models." International Journal of Educational Telecommunications, spring 2001 v7 i1 p23.

58. Wolf, David B.; Johnstone, Sally M. "Cleaning up the language: establishing a consistent vocabulary for electronically delivered academic programs." Change, July-August 1999 v31 i4 p34 (6).

59. Wolpert, Ann. "Services to Remote Users: Marketing the Library's Role." Library Trends, summer 1998 v47 i1 p21 (1).

60. Worley, Rebecca B. "The Medium is Not the Message." Business Communication Quarterly, September 2000 v63 i3 p93.

Notes 